A N N A L E S Annales de Bretagne et des Pays de l'Ouest

Anjou. Maine. Poitou-Charente. Touraine

113-4 | 2006

Varia

\title{
Les Bohémiens en Bretagne sous l'Ancien Régime
}

\author{
David D. Boutera
}

\section{(2) OpenEdition \\ Journals}

Édition électronique

URL : http://journals.openedition.org/abpo/546

DOI : $10.4000 / a b p o .546$

ISBN : 978-2-7535-1504-8

ISSN : 2108-6443

Éditeur

Presses universitaires de Rennes

Édition imprimée

Date de publication : 30 décembre 2006

Pagination : 135-158

ISBN : 978-2-7535-0405-9

ISSN : 0399-0826

Référence électronique

David D. Boutera, "Les Bohémiens en Bretagne sous l'Ancien Régime », Annales de Bretagne et des

Pays de l'Ouest [En ligne], 113-4 | 2006, mis en ligne le 30 décembre 2008, consulté le 01 mai 2019. URL : http://journals.openedition.org/abpo/546; DOI : 10.4000/abpo.546 


\title{
Les Bohémiens en Bretagne sous l'Ancien Régime
}

\author{
David. D. BOUTERA ${ }^{1}$ \\ Université de Nantes
}

C'est à Mâcon, le 24 août 1419, que des Tsiganes pénétrèrent pour la première fois dans le royaume de France. Les autorités municipales, impressionnées par cette apparition, dirent qu'ils " estoient gens de terrible stature tant en personne, en chevelx comme autrement et gisoient es champs comme des bêtes ${ }^{2}$ ". Peu de temps après cette date, de nombreuses municipalités du Sud-Est de la France exprimèrent la même surprise devant la présence de ces hommes et de ces femmes aux allures " exotiques ", qualifiés tantôt de Sarrasins, Égissiens, Égyptiens ${ }^{3}$, Bohêmes ou Bohémiens. Les groupes qui comptaient des hommes, des femmes et de nombreux enfants étaient dirigés par des chefs qui se paraient souvent du titre de comte ou de duc de "Petite Égypte ». Au mois d'août 1427, le duc égyptien André, à la tête de cent vingt Bohémiens, exhiba à Paris une lettre du pape Martin V qui ordonnait aux Tsiganes de parcourir le monde sept ans durant pour se racheter de leur apostasie ${ }^{4}$. La date de 1508 est

1. Auteur d'un mémoire de maîtrise, Les Bohémiens en Bretagne du XVe au XVII siècle, sous la direction de Dominique Le Page, Université de Nantes, 2003.

2. Asséo, Henriette, Le Traitement administratif des Bohémiens au xvIe siècle, Paris, Klincksiek, 1974, p. 14.

3. Les Bohémiens prétendirent qu'ils étaient originaires de l'Égypte ou de la Petite Égypte. Cette affirmation devait consacrer le terme d'Égyptien pour désigner ces troupes que l'on avait qualifiées durant les premières années de Sarrasins ou de Maures. À la même époque (1423), Sigismond, roi de Bohême, accordait un sauf conduit au chef d'une troupe de Bohémiens. La protection du roi de Bohême est certainement à l'origine des mots Bohême et Bohémiens.

4. D'après la chronique anonyme connue sous le nom de Journal d'un bourgeois de Paris, nous savons que les tsiganes prétendirent à leurs interlocuteurs parisiens " qu'ils se disaient très bon chrétien, et étaient de la Basse Égypte [...] Après aucun temps qu'ils eurent pris la foi chrétienne, les Sarrasins les vinrent assaillir [...] ils se rendirent à leurs ennemis et devinrent Sarrasins comme devant, et renièrent notre seigneur. " Toujours d'après cet auteur, certains quittèrent l'Égypte pour s'installer sur les terres de l'Empereur d'Allemagne et sur les terres du roi de Pologne. Mais les monarques, en apprenant leur conversion à la religion musulmane, acceptèrent leur présence à la seule condition que le pape fût consulté. Par conséquent le duc André et l'ensemble de sa troupe se dirigèrent vers Rome pour recevoir le pardon du pape. 
la plus ancienne que nous ayons pu découvrir sur la présence des Bohémiens en Bretagne. Il s'agit d'un mandement de la chancellerie de la duchesse Anne de Bretagne autorisant une troupe d'Égyptiens à traverser le territoire ${ }^{5}$ pour se rendre en pèlerinage au Mont-Saint-Michel ${ }^{6}$. L'année suivante ${ }^{7}$ et en $1522^{8}$, la chancellerie réitéra des autorisations comparables pour des compagnies égyptiennes. Aucune surprise ne se lit dans ces autorisations, il est clair que "l'administration " bretonne n'est pas perturbée par ces étranges personnages. Il semblerait qu'il n'y eût rien d'exceptionnel à croiser des Bohémiens en Bretagne au début du Xvi siècle $^{9}$. Nous estimons que la présence des Tsiganes en Bretagne pourrait dater du milieu du Xv ${ }^{\mathrm{e}}$ siècle, voire avant. Quoi qu'il en soit, à partir de cette période, les Tsiganes sont régulièrement présents dans la province jusqu'à la fin de l'Ancien Régime. Les sources qui l'attestent sont constituées par les registres de chancellerie, les registres paroissiaux et surtout les archives de la répression, qu'il s'agisse de celles du présidial, de Nantes et de Rennes, et du parlement. En effet, après avoir été relativement tolérés au $\mathrm{XV}^{\mathrm{e}}$ siècle, les Bohémiens furent victimes d'une méfiance croissante de la part des habitants de la province et de mesures de contrôle de plus en plus sévères de la part des autorités. À travers cet article, nous aimerions retracer l'évolution de la condition les Bohémiens en Bretagne à l'époque moderne en distinguant deux temps : celui des $\mathrm{XVI}^{\mathrm{e}}$ et XVII ${ }^{\mathrm{e}}$ siècles qui est marqué par la mise en place d'une répression de plus en plus sévère à leur encontre, celui du XVIII ${ }^{\mathrm{e}}$ siècle qui voit leur assimilation aux errants et vagabonds et plus largement aux populations délinquantes, ce qui nous permettra de passer en revue les délits réels ou supposés qui leur sont reprochés.

\section{D’une présence tolérée à une répression de plus en plus active}

Les documents relatant la présence de Bohémiens en Bretagne au $\mathrm{XVI}^{\mathrm{e}}$ siècle sont rares. À ce stade de nos recherches, nous pouvons ajouter aux mandements délivrés par la chancellerie de Bretagne des extraits d'une autobiographie romancée d'un certain Péchon de Ruby intitulée La vie généreuse des mercelots, gueux et Boesmiens, contenans leur façon de vivre

5. Arch. dép. de Loire-Atlantique, B 17.

6. Le texte est le suivant : "Mandement [...] pour les Egisiens estans à présent en ceste ville de Nantes de passer par le pays de Bretaigne en allant au Mont Saint-Michel ou ilz porront séjourner en faizant le voyage l'espace de trois jours ", Arch. dép. LoireAtlantique, B 18.

7. Arch. dép. de Loire-Atlantique, B 18.

8. Arch. dép. de Loire-Atlantique, B 37.

9. Nous savons que leur présence est attestée à Angers en 1498. Une opposition farouche en mars de cette année-là éclata entre la municipalité et le représentant du roi au sujet du nombre considérable d'Égyptiens impatients de rentrer dans la ville d'Angers. Sire Jean Bourjollais, connétable et échevin de la ville, donna l'ordre de les expulser du faubourg Saint-Michel mais cette décision fut contrecarrée par Pierre Pincé, le lieutenant du juge ordinaire d'Anjou. 
$[\ldots]^{10}$. Dans cet ouvrage, l'auteur retrace son adolescence aventureuse et consacre quelques pages aux Bohémiens qu'il aurait croisés par hasard dans les faubourgs de Nantes. Il dit notamment avoir rencontré « un capitaine d'Égyptiens qui estoit dans le fauxbourg de Nantes, qui avoit une belle trouppe d'Égyptiens ou Boësmiens, et me donnay à luy : il me reçut à bras ouverts, promettant m'apprendre du bien; dont ie fuz tresioreux, il me nomma Afourete ".

En dehors de cette mention, on dispose d'informations glanées dans les registres paroissiaux. Deux Bohémiens furent ainsi baptisés à Joué-surErdre le premier et le deuxième jour du mois de janvier $1582^{11}$. Le curé de cette paroisse précisa que Jean Charles, le père du premier enfant baptisé, qualifié d'écuyer et de capitaine, était le chef de la compagnie « des Égyptiens ". Il semblerait que ce Jean Charles était le capitaine égyptien qui fut engagé et protégé par Henri III ${ }^{12}$ et Henri IV, du moins si l'on en croit Tallemant des Réaux qui affirme dans ses Historiettes que le capitaine égyptien, Jean Charles, aurait conduit quatre cents hommes armés à Henri IV durant les guerres de religion ${ }^{13}$. Péchon de Ruby mentionne lui aussi un personnage du même nom qui pourrait être identifié au capitaine Charles de Joué-sur-Erdre ou, à la rigueur, à l'un de ses parents. Le 23 mai 1623, nous retrouvons des membres de la famille Charles dans une église de Hennebont où le curé baptisa Vincent Charles, fils de François Charles " cappitaine d'Égyptien " et de Marie Salvator ${ }^{14}$.

Les parrains et marraines des petits "Bohémillons " étaient très souvent des nobles. Ainsi les Rohan qui résidaient au château du Verger ${ }^{15}$ et les Cossé-Brissac parrainèrent à trois reprises des enfants de capitaines

10. PÉchon de Ruby, La Vie généreuse des mercellots, gueux et Boesmiens, contenans leur façon de vivre, subtilisez et gergon, mis en lumière par Monsieur Péchon de Ruby, Lyon, 1596.

11. « Le premier jour de janvier mil cinq quatre vingt deulx Claude Charles filz de Jehan Charles esquiyer, Égyptien capitaine des Égyptiens et de Marguerite Cheppeniees sa femme égyptienne. [...] lesquels se disent estre de la Petite Égypte. Parrain Hault et puissant Claude Auger Chevalier de l'ordre du roy notre Sire. Gentilhomme de la Chambre du roy, nostre Sire, Sieur Crappado baron de Châteaubriant. A esté marraine Damoiselle le vicompte Damre de Boysbriant en témoin de quoy j'ai signé [...] ", Arch. dép. LoireAtlantique, Microfilm, registre paroissial de Joué-sur-Erdre, année 1582.

12. Henri III témoigna sa reconnaissance dans une lettre de protection accordée à "l'escuyer égyptien Jean-Charles " : "Henry, par la Grâce de Dieu, Roy de France et de Poullongne [...] receue avons, la supplication de Jehan Charles, escuyer egyptien, natif de la petite esgipte, cappitaine de six mesnaiges, chargé de femme veufves et de petite enffans orphelins, les maryz et pères desquels sont mortz au service de noz prédécesseurs Roys, tant au camp de Saint-Jéhan Dangély, comme dict est, que de La Rochelle au faict des guerres où il auroict faict bon et fidèle service, luy estoict accordé et octroyé le sixième jour d'octobre 1573, passe port et sauf conduict, signé Charles ", Bulletin de la Société d'émulation de l'arrondissement de Montargis, n 19, séance du 25 février 1972.

13. Tallemant DEs RÉAuX, Historiettes, édition de Georges Mongrédien, Paris, t. VIII, p. 43 à 46 .

14. Arch. dép. du Morbihan, registres paroissiaux d'Hennebont, année 1623.

15. Le château se situe à Seiches, sur le Loir, en Anjou. 
bohémiens. Le $1^{\mathrm{er}}$ mars 1592, Hercule de Rohan, duc de Monbazon, pair de France, et sa nièce Madame de L'Isle parrainaient " un fils qui est aux Égyptiens ${ }^{16}$ ". Le lieutenant général de Bretagne, François de Cossé-Brissac, et ses proches descendants entretinrent une relation privilégiée avec les de La Grave. En 1631, le fils de Charles de La Grave, prénommé lui aussi Charles, fut inhumé dans l'église de Brissac ${ }^{17}$ et le 4 juillet 1645 , fut " ensepulturé dans l'église de céans le corps de René, fils de Jean Charles, escuier, capitaine d'une compagnie d'Égyptiens, et de demoiselle Marie de la Prade, son épouse ${ }^{18}$ ". Toujours dans la même église était baptisée en 1650 une petite égyptienne, Radegonde de La Haye, dont le père et la mère étaient qualifiés respectivement de "noble homme " et de " demoiselle ". Elle avait pour marraine Anne-Ursule de Cossé, marquise de La Porte.

Les relations entre les Bohémiens et la noblesse ne se limitaient pas à des liens de parrainage et il n'est pas exagéré de dire qu'il existait au Xvi et XVII ${ }^{\mathrm{e}}$ siècle un lien privilégié entre ces deux groupes sociaux, le premier ayant besoin de la protection du second pour circuler dans la province. Les compagnies bohémiennes trouvaient asile dans les châteaux de la noblesse bretonne à qui elles pouvaient rendre différents services, dont celui de fournir des forces d'appoint lors des différentes opérations militaires. En Bretagne comme dans le reste du royaume, les Bohémiens étaient alors organisés en compagnies armées composées d'un ou de plusieurs ménages ${ }^{19}$, qui se faisaient mercenaires. Dans un premier temps, ce furent les rois de France qui sollicitèrent leur aide et accordèrent en contrepartie des lettres de protection et de circulation aux chefs qui se montraient fidèles et compétents. Mais cette protection, ponctuelle s'amenuisa avec le temps. En définitive, durant tout le $\mathrm{xvI}^{\mathrm{e}}$ et le XVII ${ }^{\mathrm{e}}$ siècle, c'est la noblesse qui offrit les principaux appuis aux compagnies bohémiennes.

Péchon de Ruby signale ainsi : "Quand ils [les Bohémiens] logent en quelque bourgade, c'est tousiours avec la permission des seigneurs du pays, ou des plus apparents des lieux ${ }^{20}$. " Le premier duc de Brissac, Charles de Cossé, maréchal de France et gouverneur de Bretagne, ainsi que son fils, François de Cossé, deuxième duc de Brissac et lieutenant général de Bretagne, accueillirent durant plusieurs années une compagnie égyptienne en leur château de Brissac où ils entretenaient une véritable cour ${ }^{21}$. L'abbé Gautier, curé de Brissac, rappelait que dans cette " opulente demeure " qui conservait l'allure d'une citadelle, avec ses hautes tours, ses épaisses fortifications, ses casemates, sa prison, ses douves, son pont-levis résidait, jus-

16. VAUX DE FolETIER, F., Études tsiganes, avril 1956 (souligné par nous).

17. VAuX De Foletier, F., Les Tsiganes dans l'Ancienne France, Paris, Connaissance du Monde, 1961, p. 88.

18. VAuX DE Foletier, F., " Recherches sur l'histoire des Tsiganes dans les anciens registres paroissiaux " Études tsiganes, avril 1956, p. 6.

19. Un ménage comprenait une cinquantaine de personnes, hommes, femmes et enfants.

20. PÉCHON DE Ruby, La Vie généreuse..., op. cit., p. 49.

21. VAUX DE FOLETIER, F., "Recherches... ", art. cit., avril 1956. 
qu'au milieu du XVII ${ }^{\mathrm{e}}$ siècle, " une compagnie de gardes [...] : c'étaient des étrangers, Bohêmes ou Egyptiens [...] ". Cette garde était, selon lui, commandée par « un capitaine, d'où sans doute le nom de capitainerie donné au bâtiment voisin du château qui lui servait de résidence ". Nous ne savons ni comment ni dans quelles circonstances Charles de Cossé a pu connaître le chef de cette compagnie égyptienne qui se dénommait Charles de La Grave mais quand, au mois de mai 1629, ce dernier fut assassiné sur le chemin qui menait de Brissac aux Pont-de-Cé, il eut le droit à des funérailles solennelles : son corps fut inhumé dans l'église de Brissac avec l'autorisation de l'évêque d'Angers, en présence de plus de trois cents personnes dont la plupart étaient des Bohémiens. "Marie Moricette " la femme du défunt, offrit à la " fabrice de céans une écharpe de tafetas blanc et une taurielle ${ }^{22}$ ".

Non loin de Rennes, en 1647, le vicomte Pierre Botherel invita à plusieurs reprises la compagnie égyptienne du capitaine "Antoine Charles ${ }^{23}$ " à résider dans son château d'Apigné. Il était intéressé, quant à lui, par les connaissances des Bohémiens en matière de chevaux. Le maître d'hôtel du vicomte, François Alleaume, note dans son livre de raison qu'il avait "payé à Roulet pour un fer qu'il a mis à son cheval gris que Monsieur a eu d'avec les Egiptien ». Plus généralement, les Bohémiens participaient aux divertissements du vicomte. Les nobles appréciaient les Tsiganes pour la qualité de leur service à la chasse ${ }^{24}$. On sait enfin que les Bohémiens, et tout particulièrement les Bohémiennes, étaient considérés comme des spécialistes incontestés de la danse et en tant que tels, très recherchés lors des réceptions ${ }^{25}$. Durant l'été 1671, la marquise de Sévigné donna une soirée dans son château des Rochers, près de Vitré, au cours de laquelle un petit groupe de danseuses bohémiennes fut engagé pour divertir les invités. Le spectacle fut décevant, ce qui amena une Bohémienne à s'en prendre " à la moitié de sa compagnie ", jugeant que les membres de celle-ci étaient incapables de présenter un spectacle convenable. Elle s'excusa auprès de $\mathrm{M}^{\text {me }}$ de Sévigné : "Ils ne danseroient, ma foi, Madame, ne vous déplaise, sauf le respect qui est dû à Votre Grandeur, non plus que des balles de

22. Toiles brodées ou garnies de dentelles qui servaient dans les églises à la présentation des enfants au baptême ou à l'offrande du pain bénit.

23. Les éléments généalogiques sont insuffisants pour connaître la nature des liens familiaux entre ce capitaine Antoine Charles et Jean Charles mentionné sur l'acte de baptême de Joué-Sur-Erdre que nous avons étudié précédemment.

24. Ne voit-on pas sur la tapisserie de Tournai des Bohémiens s'affairer à vider et à découper un sanglier fraîchement chassé?

25. « Les Tsiganes dansaient dans les villes et les villages, dans les rues ou les places publiques [...] dans les palais royaux et les demeures princières. En Écosse, au palais d'Holyrood, en 1530, un groupe égyptien dansa devant le roi Jacques V et reçut un salaire de quarante shillings. Au temps de Henri IV, des Égyptiens vinrent danser un soir de juin 1607 dans une salle du château de Fontainebleau. "VAUX DE FOLETIER, F., Mille ans d'histoire des Tsiganes, Fayard, 1970, p. 136. "Molière, dans le Mariage Forcé, fait intervenir des Égyptiens et des Égyptiennes qui entrent en chantant et en dansant au son des tambours de basques. Au ballet du roi donné à la Cour avec cette comédie, en janvier 1622, Louis XIV dansa lui-même en costume d'Égyptien ", VAuX DE FolETIER, F., Mille ans..., op. cit., p. 137. 
laine. " Mais la marquise fut néanmoins charmée par l'une des Bohémiennes, à tel point qu'elle la prit en "amitié ". La jeune danseuse expliqua à $\mathrm{M}^{\mathrm{me}}$ de Sévigné que son grand-père, incarcéré dans les arsenaux des galères du roi à Marseille, était " un capitaine bohême d'un mérite singulier ». La marquise lui promit d'écrire au duc de Vivonne, général des galères, en faveur de ce capitaine " afin qu'il lui relâche un peu les fers, pourvu que cela ne soit point contre le service du roi ».

\section{La mise en place de la répression}

Cette relation privilégiée, nouée entre les seigneurs et les Bohémiens, entra rapidement en contradiction avec la législation royale. Dès 1504, Louis XII enjoignit aux officiers royaux « de faire vider le royaume " de tous les Égyptiens. Le 28 juillet 1510, le Grand Conseil promulgua un arrêt qui faisait " défense à tous autre eux disans Égyptiens et Égyptiennes de ne plus converser par le dit royaume de France, sous peine de hard ${ }^{26}$ ". Au $\mathrm{XVII}^{\mathrm{e}}$ siècle, on passa progressivement à une politique de réclusion que l'on peut définir, en reprenant les termes du sociologue Jean-Pierre Liégeois, " comme l'intégration autoritaire et généralement violente des Tsiganes dans la société qui les entoure. La disparition souhaitée géographiquement par un bannissement synonyme d'éloignement, le devient socialement par l'enfermement et l'éclatement du groupe ${ }^{27}$ ". Le 11 septembre 1635, des lettres de cachet données à Monceaux firent "injonction et commandement aux juges [...] d'appréhender et constituer prisonnier tous Égyptiens [...] pour faire et parfaire leurs procès ". En $1647^{28}$, sous la régence d'Anne d'Autriche, les Bohémiens furent menacés d'être condamnés à des peines de galères dès leur première interpellation. À partir de 1660, le processus législatif se précisa encore davantage : les conseils du Roi des années 1661 et 1662 consacrèrent nombre de leurs séances aux moyens de se procurer des forçats. Les Bohémiens devinrent une cible privilégiée ${ }^{29}$. Un édit de 1673 leur ordonna de quitter le royaume dans un délai d'un mois. Passé ce temps, ils seraient condamnés aux galères. Le texte était contresigné de Colbert et celui-ci prit un soin tout particulier à le faire appliquer. Il en adressa une copie à Arnoul, l'intendant des galères à Marseille, et aux intendants dans les généralités en soulignant qu'il n'y avait « rien de plus important que de purger toutes les provinces de ces sortes de gens ${ }^{30}$ ".

\footnotetext{
26. Arch. nat., V5/1044, 25 juillet 1510.

27. LIÉGEOIs, J-P., Tsiganes et Voyageurs, Strasbourg, Conseil de L'Europe, 1985, p. 103.

28. BNF, f. fr., ms. 4176, $\mathrm{f}^{\circ} 288$; voir aussi BNF, f. fr., ms. 4221, $\mathrm{f}^{\circ}$ 250. " Ordonnance pour arrêter les Bohémiens qui courent dans plusieurs provinces de ce royaume et les envoyer aux gallaires ", le 2 décembre 1647. La décision de 1647 signalait également l'existence, et le problème qu'ils provoquaient, des lettres de protection et des passeports de circulation dont bénéficiaient les Bohémiens : " [Les Bohémiens commettent] plusieurs larcins et pillages qui demeureroient impunis à la faveur des passeports, qu'ils ont obtenus par surprise dans le royaume " (Asś́o, Henriette, Le traitement..., op. cit., p. 27).

29. AssÉo, Henriette, Le traitement..., op. cit., p 27 et 28.

30. Ibidem, p. 29 .
} 
Ces textes qui visaient à bannir les Bohémiens du royaume ${ }^{31}$ puis à les enfermer faisaient écho à des mesures qui avaient déjà été adoptées dans certaines provinces. Le texte municipal le plus ancien que nous connaissions pour la Bretagne fut promulgué en 1631 par la municipalité de SaintPol et interdisait l'entrée de la ville aux Bohémiens après avoir fait le constat que " certaines compagnyes se disantz boysmians et un grand nombre sont proches de cette ville et ont dessain d'y venir et que par tout où ilz ont passé, ilz ont faict et commis plusieurs larcins et voleries ${ }^{32}$ ". À Vannes, le $1^{\mathrm{er}}$ avril 1672, l'assemblée municipale édicta un texte qui faisait « très expresses et itératives défens à toutes personnes se disants Égyptiens ou Bohémiens de loger en cette ville et fauxbourg ". Les Bohémiens qui ne se soumettraient pas à l'injonction d'expulsion étaient susceptibles de "punition corporelle". L'assemblée municipale menaçait les habitants qui leur donneraient asile d'une amende de 100 livres. Le texte précisait qu'ils seraient tenus pour responsables des " voleries et autres détournements " commis par les Bohémiens qu'ils hébergeraient ${ }^{33}$. Au mois de janvier 1682, le présidial de Nantes enregistra un arrêt intitulé " ordonnance au subject de la nourriture des pauvres " qui commandait " que chaque paroisse de la campagne pourvoirait à la subsistance de ses pauvres et que dans les petites villes et Bourgs considérables, l'on y ferait construire des Hôpitaux Généraux pour les renfermer pour estre nourris et entretenus des charités publiques et aumosnes ". Là encore, on s'en prit aux "Boymes " accusés de détourner et divertir les charités dues aux véritables pauvres domiciliés dans la ville et on ordonna de les poursuivre systématiquement.

Le parlement de Rennes joignit son action à celle des juridictions subalternes. Le 6 juin 1598, il adopta un arrêt sur remontrance qui faisait " commandement à tous vacabonds se disant boismiens et égyptiens de sortir hors de ce ressort dedans huitaine ${ }^{34}$ ". Au total, entre 1598 et 1641, cette cour souveraine édicta au moins sept textes (voir tableau ci-dessous) condamnant la présence des Bohémiens dans la province, soit un texte tous les six ans. En considérant le petit nombre de Bohémiens ${ }^{35}$ sous l'Ancien Régime et en prenant en compte le fait que la Bretagne n'était pas

31. LIÉGEOIS, J.-P., Tsiganes..., op. cit., p. 94. Des textes ont pu être oubliés dans ce bref recensement législatif.

32. Arch. mun. de Saint-Pol, $\mathrm{BB}^{1} 1 \mathrm{f}^{\circ} 149 \mathrm{r}^{\circ}$, exemple cité par Alain CROIX, La Bretagne aux $16^{e}$ et $17^{e}$ siècles. La vie, la mort, la foi, Paris, Maloine, 1981, t. 1, p. 92-93.

33. PAultre, Christian, De la répression de la mendicité et du vagabondage en France sous l'Ancien Régime, Paris, 1906, p. 239. À la même époque, de nombreuses villes promulguèrent des textes identiques. La ville d'Angers commanda en 1611 aux " susdits Égyptiens de déloger et s'éloigner de ceste ville et faux bourgs de cinq lieux pour le moins dedans ce jour à peine de punition corporelle ". Il semblerait que des Bohémiens étaient stationnés dans le faubourg de Bressigny, Arch. mun. d'Angers, BB 53, f ${ }^{\circ}$ 60. La ville de Toulon édicta en 1619 un texte similaire à ceux d'Angers ou de Vannes.

34. Arch. dép. d'Ille-et-Vilaine, $1 B^{\mathrm{B}}$ 98, année 1598.

35. Tous les tsiganologues s'accordent sur ce point, Il est impossible de donner une estimation. Une seule chose est certaine, c'est le nombre réduit des Bohémiens dans le royaume. 
une zone agitée par des conflits guerriers ${ }^{36}$, nous pouvons estimer que cette moyenne d'un texte tous les six ans est une moyenne élevée.

\section{Arrêts sur remontrance enregistrés par le parlement de Rennes} dans la première moitié du XVII siècle

\begin{tabular}{|c|c|c|}
\hline Dates & Injonctions & Peines en cas de non respect \\
\hline $\begin{array}{c}6 \text { juin } \\
1598^{37}\end{array}$ & $\begin{array}{c}\text { "Commandement à tous ceux }[. . .] \\
\text { Boémiens }[. . .] \text { femmes enfants } \\
\text { adultes de quitter les faubourgs de } \\
\text { Rennes }[. . .] \text { deffense de séjourner " } \\
\text { en Bretagne }\end{array}$ & $\begin{array}{l}\text { «Sans forme ni procès " les hommes } \\
\text { seront condamnés aux galères; } \\
\text { aucune précision pour la durée. } \\
\text { Aucune précision au sujet des } \\
\text { femmes et des enfants. }\end{array}$ \\
\hline $\begin{array}{l}6 \text { février } \\
1602^{38}\end{array}$ & $\begin{array}{l}\text { "Commandement à tous vacabons } \\
\text { se disant Boismiens et Égyptiens de } \\
\text { sortir }[\ldots] \text { de ce ressort sous huitaine." }\end{array}$ & $\begin{array}{l}\text { Pour les hommes : galères (durée. } \\
\text { indéterminée.) } \\
\text { Pour les femmes : fouet } \\
\text { Pour les enfants : aucune précision }\end{array}$ \\
\hline $\begin{array}{l}5 \text { sept. } \\
1615^{39}\end{array}$ & $\begin{array}{c}\text { "Injonctions et commandements aux } \\
\text { Égyptiens et Boesmiens estant dans } \\
\text { cette province de sortir d'icelle et } \\
\text { dans } 24 \text { heurs. " }\end{array}$ & $\begin{array}{c}\text { Pour les hommes : galères } \\
\text { (durée indéterminée) } \\
\text { Pour les femmes : rasées et fouettées } \\
\text { et " autres plus grandes peynes si } \\
\text { elles y eschéent." }\end{array}$ \\
\hline $\begin{array}{l}19 \text { février } \\
1630^{40}\end{array}$ & $\begin{array}{l}\text { "Commandement aux Égyptiens et } \\
\text { Boesmiens présents dans cette pro- } \\
\text { vince }[\ldots] \text { de se retirer d'icelle }[. . .] "\end{array}$ & $\begin{array}{c}\text { "Sous peine d'estre pendus } \\
\text { et estranglés." }\end{array}$ \\
\hline $\begin{array}{l}28 \text { février } \\
1636^{41}\end{array}$ & $\begin{array}{c}\text { "Constituer prisonnier tous Égyptiens } \\
\text { que vagbonds fainéants faire et } \\
\text { parfire leur procès [...] [pour les] } \\
\text { condamner suivant les } \\
\text { ordonnances }[. . .] \text { ]" }\end{array}$ & $\begin{array}{l}\text { Les peines dépendaient des } \\
\text { sentences prononcées par les juges. }\end{array}$ \\
\hline $\begin{array}{c}11 \text { octobre } \\
1641^{42}\end{array}$ & $\begin{array}{c}\text { "Commandement à tous Égyptiens } \\
\text { qui sont en cette province de vider la } \\
\text { dite province dans les } 24 \text { heures }[. . .] "\end{array}$ & $\begin{array}{c}\text { "Arrest sur peynes de la vie. " } \\
\text { "Deffense à toute personnes de } \\
\text { quelques qualités et condition } \\
\text { qu'elles soient de prester aide et } \\
\text { donner logemans et retraite aux dits } \\
\text { Égyptiens sur peine de trois } \\
\text { cens livres d'amendes." }\end{array}$ \\
\hline $\begin{array}{l}23 \text { nov. } \\
1641^{43}\end{array}$ & $\begin{array}{l}\text { L'arrêt rappelle la décision du mois } \\
\text { précédent : "Faire appréhender les } \\
\text { coupables [les Bohémiens] pour lire } \\
\text { faire et parfaire leurs procès. " }\end{array}$ & $\begin{array}{l}\text { Les peines dépendaient des } \\
\text { sentences prononcées par les juges. }\end{array}$ \\
\hline
\end{tabular}

36. Henriette Asséo écrit que les zones particulièrement perturbées par des guerres étaient fréquentées par des compagnies armées bohémiennes qui pouvaient trouver des employeurs.

37. Arch. dép. d'Ille-et-Vilaine, $1 \mathrm{~B}^{\mathrm{F}} 228$.

38. Arch. dép. d'Ille-et-Vilaine, $1 \mathrm{~B}^{\mathrm{F}} 229$

39. Arch. dép. d'Ille-et-Vilaine, $1 \mathrm{~B}^{\mathrm{F}} 230$.

40. Arch. dép. d'Ille-et-Vilaine, $1 B^{\mathrm{F}} 482$.

41. Arch. dép. d'Ille-et-Vilaine, $1 \mathrm{~B}^{\mathrm{F}} 1 \mathrm{~B}^{\mathrm{F}} 484$

42. Arch. dép. d'Ille-et-Vilaine, $1 \mathrm{~B}^{\mathrm{F}} 485$.

43. Arch. dép. d'Ille-et-Vilaine, $1 \mathrm{~B}^{\mathrm{F}} 485$. 
Certains de ces textes comme celui de 1636 constituaient l'application à l'échelle de la province de mesures promulguées par le pouvoir central ; d'autres étaient le fruit de l'initiative de la cour souveraine elle-même. Si l'on examine les peines prévues, on remarque que ce sont, en général, pour les hommes des peines de galères, et pour les femmes des condamnations au fouet et au bannissement. Les sanctions à l'égard des enfants ne sont pas précisées. La variabilité des peines d'un texte à un autre est saisissante : ainsi celui de 1615 prévoit que les Bohémiens seront condamnés à des peines de galères pour les hommes et à des peines de bannissement pour les femmes, alors que celui de 1630 se montre draconien en les menaçant d'être "pendus et estranglés ". Six ans après, par l'arrêt du 28 février 1636, le Parlement de Rennes édicta un texte plus clément qui prévoyait d'arrêter les Bohémiens pour "faire et parfaire leur procès ". En l'espace d'un mois, les Bohémiens présents dans la province pouvaient passer d'une menace de peine de mort à la garantie d'un procès qui devait définir leur sort par une "sentence définitive ". Les condamnations prévues dépendaient par conséquent des circonstances dans lesquelles elles étaient prononcées et du danger supposé que les Bohémiens faisaient courir à la sûreté générale, les textes de 1641 furent ainsi adoptés pour mettre fin aux activités d'une troupe particulièrement turbulente ; elles entraînaient par leur caractère général un processus de criminalisation de l'ensemble des gens du voyage présents dans la province, qu'ils fussent ou non délinquants. Toutefois la répétition des arrêts révèle une certaine impuissance des autorités, dont les décisions étaient souvent inappliquées et inapplicables.

C'est pour remédier à cela que la monarchie élabora un texte de référence destiné à régler de façon durable la question des Bohémiens ${ }^{44}$ : il s'agit de la déclaration du 11 juillet 1682. Après un préambule qui soulignait la faible efficacité des décisions antérieures, le pouvoir royal s'en prenait à ceux qu'il considérait comme les principaux responsables de cette situation, à savoir les seigneurs à qui on reprocha le fait " de donner retraite aux Bohémiens dans leurs châteaux et maisons ${ }^{45}$ ". Il leur était désormais formellement ordonné de cesser de protéger les Bohémiens et de les abriter dans leur domaine, sous peine d'être privés de leurs justices et de voir leurs fiefs réunis au domaine du Roi ${ }^{46}$. Les seigneurs qui se rendaient cou-

44. Asś́o, Henriette, Le traitement..., op. cit., p. 30.

45. Le 22 mai 1682, le conseil du roi avait déjà formulé un arrêt qui " faisait très expresses inhibitions et défenses à tous gentilshommes et autres personnes de leur donner retraite sous quelque prétexte ce que puisse être ». La stratégie adoptée par les rédacteurs de l'arrêt du 22 mai 1682 était de briser "l'indiscipline " des seigneurs.

46. Pour Henriette Asséo, « la sollicitude particulière des nobles à l'égard des Bohémiens fournissait, à la royauté, un moyen privilégié pour briser ces potentats locaux. La mention de gentilshommes et seigneurs justiciers visait les châtelains dans leurs attributions judiciaires. Sévissant contre les seigneurs " transgresseurs d'ordonnances", la royauté marquait d'une étape la lutte sourde que livraient les gentilshommes pour le maintien des privilèges ancestraux et loin d'être moribonds. La royauté pouvait utiliser, entre autres moyens subtils, la poursuite des Bohémiens pour retirer aux tribunaux 
pables de ce délit seraient automatiquement considérés comme " complices de leurs crimes". Le texte était complété par une série de dispositions qui s'en prenaient aux Bohémiens eux-mêmes. Ordre était donné " d'arrester et faire arrester tous ceux qui s'appellent Bohemes ou Égyptiens, leurs femmes et leurs enfants, et autres de leur suite, de faire attacher les hommes à la chaisne des forçats pour estre conduits dans nos galères et y servir à perpétuité ". Les peines prévues étaient d'une extrême sévérité : les hommes étaient menacés des galères à perpétuité, ce qui revenait à les condamner à mort ${ }^{47}$; les enfants devaient être arrachés à leurs parents pour être déposés dans les hôpitaux. Ils y seraient, disait la déclaration, " nourris et élevés comme les autres enfants qui y sont enfermés". Les mères étaient condamnées à être rasées, " la première fois qu'elles auront esté trouvées " et enfermées dans les hôpitaux. Il était rappelé que si elles persistaient à se déplacer librement, elles s'exposaient à être " fustigées et bannies hors du royaume». Les autorités provinciales soucieuses d'expulser les Tsiganes avaient désormais un texte de référence.

Si l'application de l'ordonnance de 1682 fut effective dans plusieurs provinces du royaume, on ne dispose pas d'élément sûr pour en juger en Bretagne. La volonté des autorités bretonnes d'exercer une politique répressive à l'égard des Bohémiens ne laisse pourtant aucun doute et nous avons vu précédemment que le Parlement comme les municipalités exigeaient une action à leur encontre. Nous savons de surcroît que le texte du 11 juillet 1682 fut largement diffusé dans la province. Par conséquent, tous les éléments sont réunis pour concevoir son application d'autant que la déclaration eut dans la province les mêmes conséquences qu'ailleurs.

La principale d'entre elles fut la " fragmentation " des compagnies armées égyptiennes " en petites unités discrètes ${ }^{48}$ ". En s'attaquant à la protection que les seigneurs accordaient aux Bohémiens, le pouvoir royal mit fin aux bandes de tsiganes, de cinquante, cent ou deux cents membres, commandées par des capitaines et des lieutenants, qui avaient étonné et intimidé les populations pendant plus de deux siècles. Dans ce sens, le contrôle exercé sur les Bohémiens prend sa place dans la politique de domestication de la noblesse dont on détruit la capacité à s'organiser sur le plan militaire. L'exploration des archives de la maréchaussée de Bretagne au XVIII ${ }^{\mathrm{e}}$ siècle donne un saisissant témoignage de la modification qui s'opéra en deux ou trois décennies. Les groupes de Bohémiens arrêtés dépassaient rarement dix personnes et étaient essentiellement constitués de femmes et d'enfants. Les hommes n'étaient pas présents ou de façon

seigneuriaux les causes criminelles en alléguant des protections que fournissaient leurs détenteurs aux Bohémiens ", Henriette Asséo, Le traitement..., op. cit., p. 31.

47. ZysBerG, André, Les Galériens. Vies et destins de 60000 forçats sur les galères de France 1680-1748, Paris, Seuil, 1987.

48. AssÉO, Henriette, "Les métamorphoses du métier de Bohémien en France au XVIII ${ }^{\mathrm{e}}$ siècle ", dans CROIX, Alain, DuPÂQUIER, Jacques (dir.), La France de l'Ancien Régime, Études réunies en l'honneur de Pierre Goubert, Toulouse, Privat, 1984. 
minoritaire; ils étaient aux galères ou ils se cachaient quand la maréchaussée s'approchait de leur troupe.

La deuxième conséquence de la déclaration fut la modification de la perception des Bohémiens : ceux-ci furent désormais assimilés par les autorités aux pauvres et aux errants ${ }^{49}$, à tel point qu'il est parfois difficile de les repérer dans les archives de la répression. Sur les 4298 personnes incarcérées dans la prison de Nantes entre 1752 et 1789, 1172 individus le furent pour vagabondage et mendicité ${ }^{50}$. Parmi ces derniers, seuls quatorze sont qualifiés de Bohémiens. Une observation attentive des écrous nous a permis de réaliser que ce nombre ne recouvrait qu'une partie de la réalité : grâce à l'élaboration d'une grille d'analyse plus fine ${ }^{51}$, nous avons pu identifier 27 Bohémiens supplémentaires, ce qui porte le nombre total à 41 . Pour tester notre méthode, nous avons procédé à des vérifications dans les archives judiciaires de l'année même ou de l'année qui suit la date d'incarcération, d'abord à Nantes puis à Rennes. Si à Nantes, nous n'avons trouvé qu'un seul procès mettant en cause des Bohémiens, nous en avons repéré une douzaine à Rennes, dont l'étude a prouvé que les 41 individus enfermés dans les prisons de Nantes appartenaient bien à ce groupe ethnique. Nous avons eu ainsi la confirmation qu'une observation superficielle des registres des prisons conduit à une sous-estimation du nombre des Bohémiens présents en Bretagne au XVIII ${ }^{\mathrm{e}}$ siècle et que ces populations avaient perdu aux yeux des autorités une part de leur identité pour être assimilées à la catégorie plus générale des errants.

\section{Une présence constante en Bretagne au XVIII ${ }^{\mathrm{e}}$ siècle}

Les Bohémiens continuaient pourtant à circuler dans la province, en conservant leur mode de vie, leur culture et leurs codes. Dans les années 1720, un Bohémien, dénommé J.-B. Saint-André, s'engagea dans « un régiment royal " cantonné dans " le château " de la ville de Brest. En 1725, il profita d'un congé pour se rendre avec sa mère et un cousin à la « foire fleurie de Guingamp pour acheter des chevaux pour les emmener à Rennes pour les revendre ${ }^{52}$ ». J.-B. Saint-André avoua aux forces de police que, quelques

49. Après l'ordonnance du 11 juillet 1682, le pouvoir central et le Parlement de Rennes n'ont plus adopté de textes contre les Bohémiens mais contre la mendicité et le vagabondage.

50. FARIAT, C., Les Prisonniers nantais d'après les écrous criminels du Bouffay, mémoire de maîtrise en histoire moderne, Université de Nantes, 1976.

51 . Nous avons construit une grille de lecture composée de 7 critères qui nous ont permis de les sélectionner. Ces 7 critères sont les suivants : $1^{\mathrm{er}}$ critère : arrestation en groupe; $2^{\mathrm{e}}$ critère : groupe familial; $3^{\mathrm{e}}$ critère : groupe essentiellement féminin; $4^{\mathrm{e}}$ critère : le nom des Bohémiens (les Bohémiens sous l'Ancien Régime portaient des noms qui sont souvent reconnaissables); $5^{\mathrm{e}}$ critère : particularité physique (la quasi-totalité des Bohémiens circulant en Bretagne sous l'Ancien Régime ont la peau noire ou fortement basanée); $6^{\mathrm{e}}$ critère : origine géographique des Bohémiens; $7^{\mathrm{e}}$ critère : une présence quasi-systématique d'enfants dans les groupes de Bohémiens interpellés pour vagabondage.

52. Arch. dép. d'Ille-et-Vilaine, 8 B 295 
mois auparavant, il avait déjà traversé la Bretagne de part en part. Il décrivit son parcours, citant les noms des différentes villes par lesquelles il était passé : Morlaix, Guingamp, Quintin, Carhaix, Le Faouët, Rennes, Musillac, Pontchâteau, La Roche Bernard et Nantes. Dans cette dernière ville, il avait séjourné cinq jours puis il était revenu sur Rennes pour " emmener les deux soldats qu'il avait engagés pour le régiment français à Morlaix et à Quintin ". Il fit coucher ces deux hommes à « l'auberge du Dauphin sur la place chez le nommé Chatillon ». En les ramenant à Brest, il s'arrêta avec eux à Lorient " à l'auberge de la Femme sans Tête " et le lendemain, il traversa, toujours en leur compagnie, les villes de Quimper et de Landerneau ${ }^{53}$.

Les déplacements des Bohémiens en Bretagne s’inscrivaient dans des pérégrinations plus vastes à l'échelle du royaume. Les 41 individus interpellés à Nantes entre 1752 et 1789 , soit 22 femmes, 11 hommes et 8 enfants, étaient en majeure partie originaires du sud de la France. Prenons l'exemple de trois Bohémiennes originaires de Marseille, interpellées à Nantes pour vagabondage en 1758. À l'officier de la maréchaussée qui les interrogea, elles expliquèrent qu'elles se dirigeaient vers Marseille après s'être rendues à Brest pour visiter un parent incarcéré au bagne de Brest ${ }^{54}$. En 1752, Marguerite de l'Étang, âgée de 50 ans et domiciliée à Boesnan ${ }^{55}$, traversa la Bretagne " pour voir ses deux fils qui furent condamnés aux galères ${ }^{56}$ en 1750 par le Parlement de Vienne en Dauphiné ${ }^{57}$ ". La fermeture définitive des arsenaux des galères en 1749 pour créer les bagnes donna donc l'impulsion à une circulation régulière de petits groupes de Bohémiennes entre le sud de la France (particulièrement le Dauphiné et Marseille) et Rochefort ou Brest. L'habitude de suivre un parcours plus ou moins préétabli multipliait bien évidemment le risque de se faire interpeller par la maréchaussée.

À côté de ces groupes mobiles, il existait des Bohémiens semi-sédentaires. Nous avons pu repérer, entre les années 1740 et 1780 , deux ou trois familles bohémiennes dans la ruelle du Chemineuf, située dans le faubourg de la Madeleine, à Rennes ${ }^{58}$. Parmi elles, la famille Dupré avait logé durant plusieurs années dans une auberge avant de s'installer dans une maison. Son activité essentielle consistait à parcourir les campagnes de la province pour vendre de menus produits. Des membres de cette famille étaient fiers de déclarer à un officier de la maréchaussée qu'ils s'étaient acquittés de la

53. Il s'était engagé en 1719 dans le Dauphiné avec le sieur de « Beaudreq " dans la compagnie du sieur "Sausie " qui séjourna d'abord à la frontière de Provence " pendant la contagion " (il s'agit sans doute de la grande peste de 1720 à Marseille), puis en Flandre, en Franche-Comté et enfin en Bretagne.

54. Arch. mun. de Nantes, FF 121.

55. Village proche de Grenoble.

56. Durant plusieurs années après la fermeture des arsenaux des galères et leur remplacement par le bagne, la population persistait à désigner les forçats sous le terme de galérien.

57. Arch. dép. d'Ille-et-Vilaine, 8 B 461, année 1752.

58. La ruelle du Chemineuf est une petite rue débouchant sur la rue de " la Magdelaine ". 
capitation ${ }^{59}$. Les rapports avec leurs voisins semblaient excellents : dans les années 1760, inquiétés par les services de la maréchaussée, ils durent leur libération aux nombreux témoignages des habitants ${ }^{60}$ du quartier, en leur faveur.

Cet exemple d'intégration ne doit pas dissimuler pourtant le fait que la situation des Bohémiens demeura très précaire au XVIII ${ }^{\mathrm{e}}$ siècle, en Bretagne comme dans le reste du royaume. Sans être victimes, comme ils l'avaient été au siècle précédent, de mesures générales d'exclusion, ils étaient toujours identifiés par les populations comme une catégorie à part et étaient dépendants de l'attitude adoptée à leur égard par les forces de la répression. Nous avons retrouvé 16 procès-verbaux d'arrestations opérées par les compagnies de la maréchaussée au cours du XVIII ${ }^{\mathrm{e}}$ siècle, principalement en Haute Bretagne ${ }^{61}$. Dans trois cas, les arrestations furent exécutées sans ordre préalable, soit au hasard d'une patrouille quotidienne, soit du fait d'une dénonciation d'un particulier. Le 16 mars 1729, des Bohémiennes furent appréhendées dans une métairie près de Rochefort (évêché de Rennes ${ }^{62}$ ) suite à la dénonciation d'un sieur du Buisson qui avait signalé leur présence la veille " du côté de Saint-Jacob ". De même, des cavaliers de la maréchaussée de Dol interpellèrent le 22 mai 1752 des Bohémiennes accompagnées de deux jeunes enfants ${ }^{63}$.

Dans les cas cités, les forces de l'ordre furent sans indulgence : tous les Bohémiens contrôlés furent incarcérés, comme gens sans aveu, suite à leur première interpellation. Des représentants du roi savaient pourtant se montrer plus conciliants, à l'instar du commissaire de police de Nantes, Pierre Bar, qui, le mercredi 3 mai 1752, à dix heures du matin, en passant dans la rue du Tremblay rencontra deux "Boimmienes " errantes et sans aveux auxquelles, (pour reprendre ses propos), " nous avions averty samedi et dimanche dernier de sortir de cette ville quant faute d'y obéir nous les ferions constituer prisonnière [...]; voyant qu'elles n'ont point obéi après les avoir averty [...], nous avons arrêté les deux boimmienes, ensuite les avons fait constituer prisonnières aux prisons royaux du Bouffay ${ }^{64}$ ". Il fallut, dans ce cas, une certaine forme de récidive pour que la police procède à l'arrestation des Bohémiennes, la première réaction ayant été, conformément avec ce qui avait dû être l'attitude des forces de l'ordre au cours des siècles précédents, de chercher à les chasser de la ville.

59. Arch. dép. d'llle-et-Vilaine, 8 B 467, année 1758. Un membre de la famille aurait même participé à la milice du quartier.

60. Arch. dép. d'Ille-et-Vilaine, 8 B 467, année 1758. Un commissaire du quartier certifia par lettre que les Dupré résidaient dans le quartier depuis plus de 15 ans.

61. Quatre procès verbaux d'arrestation rédigés par des cavaliers de la maréchaussée et un procès verbal rédigé par un commissaire de la Police urbaine de la ville de Nantes.

62. Arch. dép. d'Ille-et-Vilaine, 8 B 296, affaire La Fleur et Dupré, 1729.

63. Arch. dép. d'Ille-et-Vilaine, 8 B 461, affaire Marguerite de L'Étang et Marianne Pierrette, 1752.

64. Arch. mun. de Nantes, GG 764 . 
La majeure partie des procès-verbaux d'arrestation faisait suite à des ordres formulés par le prévôt de la maréchaussée de Bretagne ou par le procureur du roi, qui réagissaient au "bruit commun ", à une plainte ou à une dénonciation contre " ces particuliers Boesmiens ». S'inscrivant dans le cadre d'actions ponctuelles, ces arrestations n'en révélaient pas moins l'idée d'une de culpabilité collective de ces derniers. À la lecture des ordres donnés par les officiers de la maréchaussée, on devine une prévention à l'égard de cette population et la recherche d'un groupe particulier impliquait dans la pratique l'arrestation de tous les Bohémiens.

Un procès-verbal d'arrestation daté du 11 au 13 février 1738 est un parfait exemple de ce processus. Des cavaliers de la maréchaussée de la résidence de Dol « ayant eu avis [...] que plusieurs particuliers tant hommes que femmes estaient arrivés dans la paroisse du Vivier et s'y étaient tous retiré à coucher dans une grange [...] se transportèrent dans la dite paroisse du Vivier ". Arrivés sur les lieux vers les cinq heures du soir, ils se firent conduire dans la métairie où les Bohémiens s'étaient réfugiés et ils trouvèrent dans une grange, couchés sur de la paille, trois hommes et neuf femmes et filles, " deux desquelles ont chacune une petite fille à la mamelle [...], tous desquels nous nous sommes saisis et les avons conduits dans une auberge du dit bourg de Vivier, où pend pour enseigne La Grand Maison appartenant au Sieur Magny demeurant à Saint-Malo ». Les Bohémiens revenaient de Saint-Malo et se dirigeaient vers leurs domiciles respectifs ${ }^{65}$. Ils présentèrent aux cavaliers, qui les soupçonnaient de vagabondage, des passeports de circulation que « Monsieur le lieutenant de la ville de SaintMalo " avait validés le 10 février 1738. Le sous-brigadier Jean Gaudin, rédacteur du procès verbal et responsable de cette patrouille, constatant que " les attestations estoient renouvelées ", décida de les " lâcher après les avoir fouillés les uns après les autres ne leur ayant trouvé que des hardes propres ". La nuit tombée, les cavaliers regagnèrent leur résidence. Arrivés à destination, ils apprirent que " Monsieur le prévôt général commandant la maréchaussée de Bretagne " avait intimé l'ordre d'arrêter " une troupe de Boësmiens qui rodait dans le païs ". Il était précisé que "nous eussions à les arrêter tout ce que nous trouvions ${ }^{66}$ ". " Ayant jugé que ceux que nous venions de lacher pouvaient estre de leur troupe et avoir de faux certificat, nous avons sur le champ retournés brides à la suite desdits particuliers et les avons suivis le long de la grande routte de Saint-Malo à Pontorson le long des grèves, selon que nous les avions vû prendre ${ }^{67}$. "Le soir même, les cavaliers appréhendaient les Bohémiens. Ces derniers étaient passés, en moins de douze heures, du rang de simples Bohémiens possédant des papiers en règle au rang de Bohémiens présentant « de faux certificats » et

65. Le rédacteur du procès verbal ne précisait pas les villes où les Bohémiens étaient domiciliés.

66. Arch. dép. d'Ille-et-Vilaine, 8 B 412, procès-verbal d'arrestation daté du 11, du 12, et du 13 février 1738.

67. Arch. dép. d'Ille-et-Vilaine, 8 B 412, affaire des Bohémiens arrêtés à Vivier entre le 12 et le 13 février 1738. 
faisant partie d'une troupe de Bohémiens que le prévôt ordonnait d'appréhender.

De même, les cavaliers de la maréchaussée de Rennes, établis dans les paroisses de Saint-Germain et de Toussaint, reçurent comme leurs collègues de Dol, l'ordre « d'arrester et constituer prisonnier des particuliers Boesmiens attroupés tant dans cette ville que dans les paroisses de cette province, lesquels se font craindre et redouter dans les endroits où ils passent, lesquels Boesmiens ce font loger par force dans les endroits où ils se retirèrent et sous prétexte de dire la bonnaventure font plusieurs vols ". L'officier de la maréchaussée autorisait implicitement les cavaliers à arrêter tous les Bohémiens qu'ils pouvaient croiser. Aucun détail ne permettait de différencier un Bohémien d'un autre. L'action délictueuse d'un groupe avait des conséquences négatives pour tous les autres Bohémiens présents dans une même prévôté. Les cavaliers de la maréchaussée des brigades de Rennes, conformément aux injonctions reçues, arrêtèrent toutes les personnes qu'ils identifiaient comme étant des Bohémiens. En apprenant " qu'il y avait des particuliers tant hommes que femmes qui était dans cette ville (Rennes) lesquels étaient basanés [...]" ils se " transportèrent dans plusieurs endroits de cette ville. Nous y avons fait perquisition secrette des dits Boesmiens, nous avons fait rencontre d'un particulier bazanné de la taille d'environ cinq pieds quatre pouces vestus d'un habit canelle avec des boutons d'argent veste rouge chapeau sans bord et portant une épée garde de cuivre masquinée avec une poignée fausse et une lamme auquel particulier nous avons juré l'arrest de sa personne " Le jour même, la femme et les enfants de ce Bohémien, dénommé Pierre de la Valle dit La Ferrière, se présentaient aux portes de la prison pour s'informer des raisons de son incarcération, ce qui offrit l'occasion aux forces de l'ordre de procéder à leur arrestation.

\section{Les délits : de la réalité au merveilleux}

Le vagabondage, la mendicité (alimentaire) ou le vol de subsistance étaient les délits les plus communément imputés aux petits groupes de Bohémiens interpellés par les cavaliers de la maréchaussée. Nous avons expliqué précédemment qu'une partie des Bohémiennes interpellées en petit groupe et incarcérées dans la prison du Bouffay, à Nantes, dans la deuxième moitié du XVIII ${ }^{\mathrm{e}}$ siècle parcouraient des centaines de kilomètres pour visiter des parents enfermés dans le bagne de Brest. Ces longs périples expliquent les arrestations pour vagabondage entre Brest et Rennes, et entre Rennes et Nantes. Le 9 février 1738, "Anthoine Laval », âgé de dix ans, expliquait à l'officier de la maréchaussée, qui l'interrogeait au sujet de ses parents et de leur mode de subsistance, que la mendicité était un expédient couramment employé. Venant de Montpellier et se dirigeant vers la Normandie, ils avaient traversé la Bretagne, " pour survivre, ils vendaient leurs hardes, puis ils mendiaient leur vie quand c'était nécessaire ${ }^{68}$ ".

68. Arch. dép. d'Ille-et-Vilaine, 8 B 412, interrogatoire d'Antoine Laval du 9 février 1738. 
Parfois la maréchaussée s'ingéniait à savoir si les Bohémiens qu'elle appréhendait pour vagabondage n'étaient pas les auteurs de vols perpétrés dans la circonscription. Au début du mois d'août de l'année 1752, les cavaliers de la maréchaussée de Châteaubriant capturèrent dans une grange du bourg d'Auverné un groupe de Bohémiennes. Le prévôt de la maréchaussée de Nantes déclara à chacune des Bohémiennes qu'il interrogeait qu'elle était " accusée d'être Bohémienne, voleuse, diseuse de bonne aventure, vagabonde et sans adveu ${ }^{69}$ ". Pour sa défense, une des Bohémiennes interrogée répondit " qu'elle n'était pas une voleuse, ni une diseuse de bonne aventure. Elle n'était pas une vagabonde parce que les hivers elle se retirait dans une petite chambre dans les endroits où elle se trouvait ${ }^{70}$ ". La maréchaussée les laissa enfermées dans les prisons pour un complément d'enquête. Les quelques témoins réunis à la mi-décembre 1752 démentirent en partie les accusations formulées par le procureur du roi à leur encontre. Jacques Tindret, drapier au Bourg de d'Auverné, affirma qu'à la " fin du mois de juillet dernier arrivaient au Bourg Dauverné cinq Bohémiennes avec des petits enfants à qui il donna le couvert. Elles ne lui firent aucun tord ${ }^{71}$ ". L'aubergiste du bourg, Thomas Guimené confirma la présence des 5 Bohémiennes au début du mois d'août. Elles se seraient introduites dans le cabaret pour y dire la bonne aventure «à tous ceux qui se présentaient et elles recevaient ce que l'on voulait bien leur donner "; il ponctua sa déclaration en expliquant « qu'il avait entendu dire qu'elles n'avaient causé aucun tord dans les endroits où elles étaient passées ${ }^{72}$ ". Le prêtre vicaire de "Dauverné " affirma que les Bohémiennes incarcérées dans les prisons avaient " mendié leur vie en allant de porte en porte [...] deux des femmes disaient la bonne aventure à ceux qui se présentaient ${ }^{73}$ ". D'après les témoignages, les Bohémiennes n'avaient commis aucun vol. La bonne aventure et la mendicité étaient, semble-t-il, les seuls reproches à leur faire.

Il semblerait cependant qu'au cours du XVIII siècle, trois, peut-être quatre, bandes de 10 à 30 Bohémiens se déplacèrent librement en Bretagne. Nous sommes sûr de cette présence pour trois d'entre elles. La première et certainement la plus intéressante circula entre Guingamp et Rennes au début des années 1720. La maréchaussée parvint à interpeller trois de ses membres ${ }^{74}$. La seconde bande, certainement la plus nombreuse, était présente en Bretagne dès l'année 1738. La troisième bande parcourait la province entre 1769 et 1771 . Toutes ces bandes, et tout particulièrement celle de 1720 , se signalèrent par des délits originaux : la " manipulation " de la monnaie et le " négoce chimérique ".

69. Arch. dép. de Loire-Atlantique, B 8708, année 1752.

70. Arch. dép. de Loire-Atlantique, B 8708, année 1752.

71. Arch. dép. de Loire-Atlantique, B 8708, année 1752, déposition de Jacques Trinchet.

72. Arch. dép. de Loire-Atlantique, B 8708, année 1752, déposition de Thomas Guimené.

73. Arch. dép. de Loire-Atlantique, B 8708, année 1752.

74. Le procès de ces trois personnes a commandé l'intervention de 140 témoins. Nous avons estimé que la liasse contient plus de mille pages. 
Trois types de manipulations peuvent être distingués : la fabrication de fausse monnaie, la diffusion de fausse monnaie et le " vol au rendez-moi ". Pour ce qui concerne la fabrication de la fausse monnaie, il semble que certains Bohémiens procédaient en deux étapes. Ils s'efforçaient, dans un premier temps, de récupérer une quantité importante de petite monnaie en utilisant une pièce de grosse valeur pour acheter un petit objet ou un peu de nourriture. Ils demandaient à leur interlocuteur de leur rendre la différence en petite monnaie : Gilette Richard, femme d'un métayer au Rocher (paroisse de Montgermont), expliqua aux cavaliers de la maréchaussée qu'en 1769 « une Boymienne et un Boymien lui achetèrent une demi-douzaine d'œufs. Ils lui donnèrent une pièce de 24 sols dont ilz demandèrent la monnaie. Mais ils refusèrent en échange des sols marqués. Ils préféraient des pièces de deux liards ${ }^{75}$ ". En 1771, Roze Ernault, habitant le bourg et la paroisse de Moulin, se rappelait que "trois Böesmiens à savoir deux femmes et un homme entraient chez elle pour acheter du tabac. Elle dut échanger de la monnaie sur un écu de trois livres [...]; ils (les Bohémiens) cherchaient de petits liards et des pièces de deux liards et d'un sol, que ceux-là ou d'autres sont retournés chez elle acheter du tabac et demander de la monnaie sans s'être apperçu qui luy a fait tord ${ }^{76}$ ". Après avoir récupéré une quantité importante de menue monnaie ou de pièces particulières (écus marqués à la vache ou deniers marqués de la fleur de lys), les Bohémiens procédaient à la deuxième étape qui consistait à fabriquer de la fausse monnaie en "maquillant " la petite monnaie. Les faussaires s'ingéniaient à modifier sa valeur en essayant de l'augmenter. Françoise Lorion, femme d'un laboureur de Saint Laurent, prétendit qu'entre 1767 et 1768 des "Boesmiens et des Boesmiennes, qui demeuraient à Maison Blanche paroisse Saint-Grégoire " lui proposèrent de leur échanger de la monnaie. Elle expliqua aux cavaliers de la maréchaussée " que les Boesmiens et les Boesmiennes blanchissaient cette monnaie, ils convertissaient les pièces d'un sol en écu de trois livres, les pièces de deux liards en pièces de 24 sols et les liards en pièces de 12 sols ". Peut-on parler d'une réelle fabrication de fausse monnaie? Ce crime très grave exigeait de nombreuses opérations spécifiques comme la fonte de métal et la création de moules. Les faussaires que nous étudions exerçaient plutôt la falsification en maquillant de vraies pièces. Une marchande de la paroisse de Saint-Georges de Rennes, Perrine Vallée, affirma qu'en 1769 un jeune homme assez bien vêtu vint lui apporter une pièce de 24 sols dont il lui demanda la monnaie, ce qu'elle fit. Le lendemain, elle s'aperçut que cette pièce de 24 sols n'était autre chose qu'une pièce de deux liards blanchie et frappée comme une pièce de 24 sols. Il semble que la plupart des personnes sollicitées pour échanger de la monnaie étaient au courant de cette pratique, ce qui pourrait laisser penser à une possible complicité. Les instigateurs de l'échange monétaire offraient des profits à ceux qui l'acceptaient. En 1738, Pierre Lucas, pro-

75. Arch. dép. d'Ille-et-Vilaine, 2B 1886, année 1773

76. Arch. dép. d'Ille-et-Vilaine, 2B 1886, année 1773. 
priétaire de l'auberge L'Écu de France, située à la Chapelle Chaussée, reçut la visite "à nuit brunéante d'un particulier petit et robuste qui avait des culottes rouges et une particulière de petite taille disant être sa femme depuis deux mois [...]. Ces deux-là étaient suivis d'un particulier Bas-Breton qui leur portait un paquet de hardes ". Après s'être installés dans leur chambre, le " particulier Bas-Breton descendit par hasard dans la cuisine et fit savoir à l'aubergiste que les époux changeaient de l'argent. Le lendemain, ils descendaient et s'informaient pour savoir s'il avait pu trouver des sols marqués à \&.L et à l'aigle et des écus marqués à la vache en proposant du profit. Le déposant leur présenta 10 sols marqués à \&.L pour lesquels ils lui donneraient 6 sols de profits ${ }^{77}$ ". À la fin des années 1760, Françoise Cullial, du village de Teillair (paroisse du Pyré), expliquait aux cavaliers de la maréchaussée qui l'interrogeaient que " deux Bohémiennes lui donnaient 2 sols de bénéfice par pièce de 12 sols ; 4 sols de bénéfice par pièce de 24 sols; 10 sols de bénéfice par écu de 3 livres et 20 sols de bénéfice par écu de 6 livres ${ }^{78} "$.

Demander un type de monnaie spécifique permettait deux délits possibles. Le premier consistait, nous venons de le voir, à falsifier des monnaies de petite valeur. Le deuxième amenait à pratiquer le « vol au rendezmoi ", c'est-à-dire, lorsque l'on changeait des pièces, "à feindre de chercher parmi elles tel millésime ou telle effigie, et à en escamoter le plus possible $^{79} "$. Certains Bohémiens, au moment de régler leur note chez un commerçant, s'ingéniaient à donner une pièce avec un fort pouvoir d'achat. Leur interlocuteur, dans l'obligation de rendre beaucoup de monnaie (d'autant que les Bohémiens précisaient qu'ils souhaitaient recevoir la différence avec de la menue monnaie), était contraint de sortir un grand sac ou une boîte contenant en grande quantité des monnaies de petite valeur. L'attitude la plus courante était de prendre la boîte ou le sac rempli de monnaie des mains de la victime et de verser son contenu sur la table en feignant de chercher son dû. La rapidité et l'agilité devaient assurer à l'auteur de cette manipulation un gain appréciable.

\section{Le négoce chimérique}

Pour la plupart ces délits n'avaient rien de vraiment exceptionnel dans leur conception et leur réalisation. Il existait des faits beaucoup plus originaux et surtout beaucoup plus rocambolesques, qui demandaient, à l'instar des délits précédents, une grande dextérité dans la manipulation mais également un grand pouvoir d'imagination et de persuasion. Le négoce chimérique fait partie de ces délits hors normes : son nom vient d'une expression inventée par les officiers de la maréchaussée de Rennes (1725) pour qualifier une escroquerie minutieusement préparée faisant intervenir à la

77. Arch. dép. d'Ille-et-Vilaine, 8B 412.

78. Arch. dép. d'Ille-et-Vilaine, 2B 1886, année 1773.

79. VauX de Foletier, Le Monde des Tsiganes, op. cit., p. 181. 
fois " des faits surnaturels " et des croyances ancestrales. Il consistait à faire croire à un individu que, sur son terrain ou dans sa maison, se cachait un important trésor gardé par le diable ou les esprits. Les Bohémiens faisaient entendre à l'individu concerné qu'ils avaient le pouvoir d'invoquer ces derniers ${ }^{80}$ puis ils proposaient au propriétaire du terrain de parlementer avec le gardien surnaturel du trésor pour connaître les conditions de sa libération. Pour " lever " le trésor, les Bohémiens expliquaient à la victime qu'un don en argent serait de nature à apaiser le diable et ils s'engageaient, une fois le trésor récupéré, à le partager de façon équitable.

Le 12 juillet 1724, " au environ du soleil couchant deux hommes et une femme fort basanés de visage demandaient à loger " à Anne Le Roux, propriétaire d'une auberge à " Perret-Treuc ". Ces trois Bohémiens, dénommés Philippe Saint-Aignan, Jean Baptiste Saint-André et Marguerite Saint-André, déclarèrent, à leur interlocuteur, être marchands et qu'ils se dirigeaient vers la " foire de la Martire ". La dernière nommée expliqua à Anne Le Roux et à son mari, René Mesnard, que la cave de la maison cachait un trésor gardé par le diable, dont on pouvait s'emparer en faisant à ce dernier un don en argent de 42 écus. Avant de descendre au sous-sol, les Bohémiens aspergèrent l'ensemble des individus présents d'eau bénite à l'aide d'une branche de buis. Arrivés à la cave, ils s'agenouillèrent et invitèrent le couple à se joindre à eux pour " prier Dieu ». " Les trois particuliers parlaient hautement, en forme de prière un jargon auquel ils [le couple] ne pouvaient comprendre un mot ". La Bohémienne se saisit de l'argent [le don destiné au diable] et l'enveloppa dans un linceul ${ }^{81}$ qu'elle plia en forme de croix. Le lendemain, elle convoqua le couple à la cave pour lui demander d'enfermer le linceul dans une barrique. Le rituel de l'eau bénite fut réitéré; les murs et le sol de la cave comme l'ensemble des participants en furent aspergés. La scène était illuminée par des cierges préalablement bénits. Les participants durent à nouveau s'agenouiller pour prier Dieu. Une fois la cérémonie terminée, les Bohémiens emportèrent des cierges dans leur chambre, expliquant que la nuit serait longue et mouvementée mais ils assurèrent qu'il ne fallait pas s'inquiéter " du bruit et peut être des cris qu'ils entendraient durant cette soirée ". Le lendemain matin, la Bohémienne demanda à ses logeurs « s'ils n'avaient pas entendu le carillon qui avait sonné toute la nuit ». Devant leur réponse négative, elle leur expliqua qu'elle devait aller avec ses compagnons en pélerinage à la ChapelleSaint-Sauveur afin de libérer le trésor et promit de revenir dans la semaine. Cette promesse ne fut bien entendu pas respectée et, quand au bout de huit jours, René Mesnard ouvrit la barrique, il dut constater que l'argent avait été subtilisé ${ }^{82}$.

80. Une Bohémienne affirmait en 1725 à un habitant de Tréfou : « Je parle quand je veux aux esprits qui gardent les trésors ", Arch. dép. d'llle-et-Vilaine, 8 B 295.

81. Un drap.

82. Arch. dép. d'llle-et-Vilaine, 8 B 295, année 1725. 
La plupart des Bohémiens qui s'illustrèrent dans ce genre d'escroquerie sur le territoire breton se présentaient comme des ressortissants anglais. Au début du mois de février 1738, trois Bohémiennes arrivèrent chez Guillaume Bourjault, qui était le fermier du prieuré de Saint-Pétreu ${ }^{83}$, appartenant à l'abbaye de Tronchet. La plus âgée des Bohémiennes, " une particulière bazanée ", sollicita le gîte pour elle et ses compagnes. Le lendemain, elle interpella son logeur : "Vous ne savez pas qui nous sommes, ni qui nous amène ici, ma sœur et moi sommes Anglaises [...] C'était autrefois, ici, notre demeure, nous en avons été chassées pour la religion de nos ancêtres. Ils ont caché de l'argent [...] nous le savons par les papiers que nous avons [...]. Si vous voulez vous intéresser avec nous, nous vous mettons d'un tiers et jamais ni vous, ni votre famille ne serez pauvres. " Elle expliqua au futur escroqué que le trésor était gardé par le diable : « Au bout d'un certain temps qu'un trésor est caché les diables en prennent possession. On ne peut ravoir l'argent qu'avec l'argent et l'or avec de l'or. " Guillaume Bourjault fut effrayé à l'idée d'avoir affaire avec le diable et refusa de chercher ce trésor. Les Bohémiennes le rassurèrent en prétendant qu'il n'aurait pas à le rencontrer et lui promirent qu'" elles se chargeraient du diable en lui enlevant de ses mains le trésor ». Mais au préalable, Guillaume Bourjault devait leur donner 18 livres car selon l'expression précédemment citée, l'argent attire l'argent et l'or attire l'or. Une fois la somme réunie, les deux Bohémiennes et la future victime se dirigèrent vers le cellier où ils enveloppèrent l'argent dans de la "filasse ". La plus âgée " fit plusieurs signes de croix sur le paquet et le jeta dans une barrique vide interdisant au déposant [Guillaume Bourjault] d'y jeter un œil au risque que le diable lui torde le col ». Elle expliqua que la réussite du projet demandait quelques jours de patience, temps pendant lequel elle et sa compagne devaient s'en aller " pour faire dire des messes pour 9 francs ". Avant de partir, elles " demandèrent de l'eau bénite et un cierge bénit parce que cela était nécessaire pour exorciser le diable ". La femme du fermier dut sacrifier deux draps de qualité pour la réussite de l'opération : " La particulière demanda deux drap de lit des meilleures et des plus forts pour enlever le trésor et qu'elles les ferait bénir dans les endroits où elle ferait dire des messes. " Elle apporta un drap qui, en définitive, ne convenait pas à la Bohémienne qui le jugea trop petit. Elle se rappela " que la veille, elle en avait mis un neuf sous ses enfants. Elle alla le chercher et l'apporta à la dite particulière ". Quelques jours après le départ des Bohémiens, le couple décida d'ouvrir la barrique et constata en fouillant le paquet " de filasse " que l'argent avait été remplacé par un caillou ${ }^{84}$.

Certaines victimes du négoce chimérique s'interrogeaient sur les moyens employés par les Bohémiens pour communiquer avec le diable. Au mois d'avril 1725, un laboureur de Beaunay, de la paroisse de Bréhant, qui offrait 70 écus pour lever un trésor, apprit de la bouche de la

83. Paroisse de "Plérier ", évêché de Dol.

84. Arch. dép. d'Ille-et-Vilaine, 8 B 412, année 1738. 
Bohémienne « qu'il [le diable] ne manquerait de lui [à la Bohémienne] apparaître sous forme d'un chien, d'un dindon, ou de quelque autre animal ${ }^{85}$ ". Le 26 avril 1725, François Halé habitant le village de "Veauhen ${ }^{86}$ " demanda à la Bohémienne sous quelle forme lui apparaissait le diable : " Le diable, disait-elle, lui vient sous la figure d'un coq ou d'une dinde ${ }^{87}$. " Les modesties de son apparence ne faisaient pas pour autant du diable un partenaire conciliant : dans tous les cas, il fallait le satisfaire grâce au don d'une importante somme d'argent, qu'il n'était pas question de négocier. À un couple qui était dans l'impossibilité de rassembler la totalité de la somme exigée, une Bohémienne expliqua que le diable, qu'elle avait informé du problème, ne voulait pas « rabattre de cinq sols par mil écu et que le trésor était considérable $^{88}$ ".

Le trésor incitait certains métayers " à voler » leur propriétaire. En 1725, à la veille de la Saint-Jean, Gildas Laillé " ménager " de cinquante ans habitant la métairie de l'Euriza ${ }^{89}$ rencontra deux Bohémiennes qui lui assurèrent qu'un trésor était caché " aux environs de sa maison ". La métairie appartenant à Monsieur de Cambout, l'une d'entre elles formula le désir, feint ou sincère, de le rencontrer afin de l'associer à la recherche et au partage des profits qui seraient réalisés. Mais sa compagne l'en dissuada : " Ma mère si vous allez parler à Monsieur de Camboul et lui dire votre secret il viendra [...] et il lèvera le trésor et nous n'aurons rien au lieu que si ces bonnes gens [Laillé et sa famille] veulent aider et se joindre avec nous nous lèverons le trésor et le partagerons par moitié et en même temps ${ }^{90}$. " Gildas Laillé n'hésita pas une seule seconde et accepta de s'associer avec Bohémiennes sans avertir son propriétaire.

Toutes ces histoires, puisées dans les archives judiciaires, informent sur l'univers culturel des paysans bretons au XVIII ${ }^{\mathrm{e}}$ siècle. Les gens des campagnes faisaient preuve en apparence d'une très grande crédulité. Le fils d'un dénommé Corbel qui fut abusé par l'escroquerie du négoce chimérique avoua aux cavaliers de la maréchaussée qui l'interrogeaient l'aveuglement complet de tous les membres de sa famille. Il expliqua qu'au moment de quitter la ferme, les Bohémiens avaient demandé qu'on leur prête un manteau pour couvrir un des leurs car la pluie tombait abondamment : "Ce qui lui fut donné avec une facilité si grande [...] on leur donnait tout ce qu'ils auraient demandé étant tous comme ensorcellé, comme s'ils eussent été parvenues pour eux par quelques charmes. " L'appât du gain, la cupidité peuvent aider à comprendre ces comportements mais ils n'expliquent pas tout. Les paysans continuaient à baigner dans un univers magique où il semblait presque naturel d'invoquer le diable pour obtenir

85. Arch. dép. d'Ille-et-Vilaine, 8 B 295.

86. Paroisse de "Tréguenel ", évêché de Dol.

87. Arch. dép. d'Ille-et-Vilaine, 8 B 295, déposition de François Halé.

88. Arch. dép. d'Ille-et-Vilaine, 8 B 295, déposition de Louise Le Fanaurou.

89. La métairie se situait dans la paroisse de Guerren dans l'évêché de Nantes.

90. Arch. dép. d'Ille-et-Vilaine, 8 B 295. 
satisfaction, surtout pour obtenir de l'argent qui relevait toujours, semblet-il, du domaine du diabolique. Les Bohémiens se chargeaient de rassurer ceux qui avaient peur d'offenser Dieu. À une femme effrayée, une Bohémienne répondit : "Qu'il n’y avait point de péché pour enlever le trésor parce qu'il était de l'argent qui perdait. On en pu faire beaucoup de charité aux pauvres et aux religieux mendiants, pour prier le seigneur pour le repos de l'âme de ceux qui ont caché le trésor ${ }^{91}$."

Dans ce schéma, les Bohémiens étaient assimilés à des sorciers, à des magiciens qui pouvaient entrer en communication avec le diable. Si certains paysans montraient une certaine méfiance à leur encontre, ce n'est pas tant pour les pouvoirs qu'on leur prêtait que pour leur capacité à les utiliser pour leur propre enrichissement. Un habitant de Tréguenel, François Halé, intéressé par le trésor, avouait ainsi qu'il se « défiait d'eux voyant qu'ils [les trois Bohémiens] parlaient au diable, craignant que ce ne fussent des magiciens et qu'ils partent avec le trésor sans rien lui donner ${ }^{92} "$.

Les réalités décrites pour les $\mathrm{XVI}^{\mathrm{e}}$ et $\mathrm{XVII}{ }^{\mathrm{e}}$ siècles demeurent valables au $\mathrm{XVIII}^{\mathrm{e}}$ siècle ${ }^{93}$. Les paysans, ou au moins certains d'entre eux, continuaient à mélanger des éléments sacrés (eau bénite, cierge, pèlerinage, messes), le diable (symbolisé par des animaux comme les poules et les chiens), et percevaient les Bohémiens comme des sorciers capables de mettre en relation ces différents univers. Personnages étranges par leur mode de vie, ils exerçaient une fascination sur les populations sédentaires qui pouvaient par là même se laisser séduire par les histoires qu'ils racontaient.

Cette fascination pouvait tourner au rejet quand des phénomènes inexpliqués survenaient dans les campagnes, notamment des incendies. Le préjugé du Bohémien incendiaire est une suspicion largement répandue dans la France de l'Ancien Régime, surtout quand certains Bohémiens avaient eu maille à partir avec des paysans. Nous avons trouvé un exemple de cela en Bretagne, où en 1724, une rumeur de Bohémiens incendiaires courut la ville de Saint-Brieuc. Un témoin, $\mathrm{M}^{\mathrm{me}}$ Le Pezan, dont le mari avait vendu des pistolets à des Bohémiens, affirma que ceux-ci avaient mis le feu à une maison de la paroisse de "Pommeré " et décrivit avec un luxe de détails, comme si elle avait assisté elle-même à la scène, ce qui n'était pas le cas, que " ces Bohémiens allaient de maison en maison [pendant l'incendie] crier au feu à dessein de les [les habitants] voler une fois sortis ". Son témoignage fut toutefois contredit par celui d'une autre personne, Françoise Friont, qui expliqua qu'elle avait effectivement entendu que des Bohémiens avaient commis des vols depuis quelques mois dans le pays et qu'une maison avait brûlé dans la paroisse de "Pommeré "; toutefois, selon elle, rien ne permettait d'affirmer que l'incendie était volontaire et dans tous les cas,

91. Arch. dép. d'Ille-et-Vilaine, 8 B 295.

92. Arch. dép. d'Ille-et-Vilaine, 8 B 295.

93. CroIX, Alain, Cultures et Religion en Bretagne au XVI siècle et XVII siècle, Rennes, Apogée, 1995, p. 168. 
on ne pouvait l'attribuer à des Bohémiens, aux dires même des habitants du lieu ${ }^{94}$. Même si elle était discutée, l'image du Bohémien incendiaire vint se rajouter au tableau négatif que les populations sédentaires s'étaient faite progressivement, de ces nomades désormais perçus comme dangereux.

Les Bohémiens connurent globalement en Bretagne la même évolution que dans le reste du royaume : apparus dans la province dès la fin du Moyen Âge, ils furent d'abord relativement tolérés du fait qu'ils étaient considérés comme des pèlerins et non comme des vagabonds. Organisés en compagnies, ils bénéficièrent de la protection occasionnelle de la monarchie et plus systématiquement de celle de la noblesse qui trouva en eux les troupes indispensables pour défendre ses châteaux ou pour mener ses opérations guerrières. Mais au fil du XVI ${ }^{\mathrm{e}}$ siècle, l'attitude des populations et des autorités provinciales à leur égard se modifia. Ils acquirent une réputation de pilleurs et firent l'objet d'une répression de plus en plus sévère, dont l'ordonnance de 1682 constitua le point d'orgue. Confondus désormais avec le vaste troupeau des vagabonds et des errants, ils virent leurs déplacements strictement surveillés et les compagnies se fragmentèrent en groupes plus réduits, composés surtout de femmes et d'enfants, alors que les hommes devenaient des victimes de choix pour les galères puis pour les bagnes. Ils n'en cessèrent pas moins d'exercer une fascination mêlée de crainte sur les populations rurales pour lesquelles elles constituèrent incontestablement un agent d'ouverture sur le monde.

94. Arch. dép. d'Ille-et-Vilaine, 8B 295. 


\section{RÉSUMÉ}

En Bretagne, comme ailleurs en France, les populations tsiganes sont soumises à une répression sans cesse plus féroce, en particulier à partir du règne de Louis XIV. Auparavant tolérées dans les campagnes, voire protégées par des seigneurs qui s'en servaient comme de milices, les compagnies de " Bohèmes " sont désormais pourchassées et dissoutes. Assimilés à des vagabonds, jetés aux galères ou enfermés dans les hôpitaux, les Tsiganes survivent toutefois, tout au long du $\mathrm{XVIII}^{\mathrm{e}}$ siècle, dans le paysage de la Bretagne rurale où les archives judiciaires attestent de leur présence à la fois fascinante et inquiétante.

\section{ABSTRACT}

In Brittany like elsewhere in France, Tzigane populations are submitted to a ferocious repression, in particular as from the reign of Louis XIV. Before tolerated in the countryside and sometimes protected by lords who used them as a militia, les companies de "Bohêmes" are since then pursued and dissolved. Assimilated to tramps, thrown on galleys or shut into hospitals, Tziganes still survived during the whole $18^{\text {th }}$ Century in the landscape of rural Brittany where judiciary archives testify of their presence at the same time fascinating and disquieting. 